Author: Wit Grzesik

Title of article: „Hybrydowe procesy skrawania wspomagane mediami technologicznymi” (“Media-assisted machining processes”)

Mechanik, Vol. 91, No. 12 (2018): pages 1050-1056

DOI: https://doi.org/10.17814/mechanik.2018.12.186

\title{
Media-assisted machining processes
}

\author{
Hybrydowe procesy skrawania \\ wspomagane mediami technologicznymi
}

\section{WIT GRZESIK *}

\begin{abstract}
A special group of hybrid assisted processes termed mediaassisted processes which apply various liquid and gaseous media supplied to the cutting zone is highlighted. Special attention is paid on such cooling techniques as highpressure machining (HPC), high-pressure jet assisted machining (HPJAM), minimum quantity cooling/lubrication (MQC/MQL) and a group of cryogenically cooled machining including such cryogenic media as $\mathrm{CO}_{2}$ snow and liquid nitrogen $\left(\mathrm{LN}_{2}\right)$. Some important effects resulting from the various cooling strategies are outlined and compared. In particular, quantitative effects concerning chip breaking, thermal and tribological behavior of the cutting process as well as burr reduction, surface quality and subsurface layer are presented. The optimization procedure concerning both energy consumption and machining costs in terms of material removal rate (MRR) is presented.
\end{abstract}

KEYWORDS: hybrid machining, cooling strategies, cooling media, high-pressure machining, minimum quantity lubrication, cryogenic machining, difficult-to-machine materials

The paper is a continuation of the author's previous publications in the monthly Mechanik [1-3] devoted to hybrid machining processes and its importance in modern manufacturing industry. It develops the problem of supporting the cutting process by introducing additional liquid and / or gas media into the cutting zone.
In the general classification of hybrid shaping processes [1.4], the first group is distinguished by assisted processes (subgroup I.A) and combined (mixed/joint processes subgroup I.B). In the case of conventional and unconventional processes, the most important is the creation of hybrid processes according to the principle of $\mathrm{I}$. $A$, that is the support of various methods of vibration energy cutting, thermal laser and liquid and gas media. Hybrid processes with support for liquid and gas media will be marked with the CM+TM symbol.

The characteristics and effects of the application of various cooling and lubrication strategies (dry, MQL and cryogenic) in the cutting process are presented in the tab. I. They are inseparably connected with the tendency to increase the sustainability (sustainability) of the cutting process, which is approximate in the article [6].

In the early 1970 s, when cutting tool coatings began to be used on the industrial scale, it seemed that dry cutting could be used to a much greater extent. However, for four

decades failed to achieve the required progress in surface engineering of thin-film materials resistant to wear and in the early 90 s began to be introduced to the industry of semi-dry machining, commonly known as machining with a minimum use of CCS (MQL - minimum quantity lubrication) as a new sustainable machining strategy.

It allowed a significant reduction in the use of coolants/lubricants, but there were further barriers in improving the cutting process, such as tool life or surface quality / TSL state (technological surface layer).

TABLE I. Characteristics and application of various cooling and lubrication strategies in the cutting process [5]

\begin{tabular}{|c|c|c|c|c|c|c|}
\hline & \multirow[b]{2}{*}{ Type of influence } & \multicolumn{5}{|c|}{ Cooling/ lubricating strategy } \\
\hline & & $\begin{array}{c}\text { Flood } \\
\text { (emulsion/oil) }\end{array}$ & $\begin{array}{c}\text { Dry } \\
\text { (compressed air) }\end{array}$ & MQL (oil) & Cryogenic $\left(\mathrm{LN}_{2}\right)$ & $\begin{array}{c}\text { Hybrid } \\
\left(\mathrm{LN}_{2}+\mathrm{MQL}\right)\end{array}$ \\
\hline \multirow{3}{*}{ 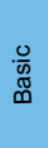 } & Cooling & good & poor & marginal & very good & very good \\
\hline & Lubricating & very good & poor & very good & marginal & very good \\
\hline & Chip evacuation & good & good & marginal & good & good \\
\hline \multirow{4}{*}{ 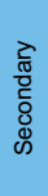 } & Machine tool - cooling & good & poor & poor & marginal & marginal \\
\hline & Workpiece - cooling & good & poor & poor & good & good \\
\hline & Dust/particles - control & good & poor & marginal & marginal & good \\
\hline & Product quality & good & bad & marginal & very good & very good \\
\hline
\end{tabular}

\footnotetext{
* Prof. dr hab. inż. Wit Grzesik (w.grzesik@po.opole.pl) - Katedra

Technologii Maszyn i Automatyzacji Produkcji Politechniki Opolskiej
} 
Like traditional CCS, aerosols also have a negative, although smaller, impact on the environment and health of employees [7]. This strategy does not work well for hard-tocut materials such as hardened steels, superalloys or composite materials. Therefore, it was necessary to introduce another sustainable machining strategy, based on the concept of dry machining with a rapid cooling effect, using cryogenic media (liquid LN2, cooled $\mathrm{CO}_{2}$, cooled air), individually or hybrid, e.g. LN2 from MQL (tab. I).

\section{Hybrid cutting methods with technological media assistance}

n Machining with high pressure CCS. Among the cutting processes assisted by technological media, it is important to supply CCS under high pressure, mainly to improve the machinability of hard-to-cut materials - nickel and titanium alloys, ceramics, composite materials and corrosion resistant steels. Research in this area has been conducted for several decades, and their initiation is attributed to Iscar, which at the beginning of the 90s introduced a highpressure CCS supply system for cut-off and grooving tools called Jetcut. In turn, the dissemination of the HPC machining concept is a merit of Sandvik Coromant, which used it in various variants of turning, milling and drilling tools.

As it is commonly known, the effect of directing the liquid stream under the appropriate pressure between the chip and the rake face is to create a hydrodynamic wedge that changes the contact conditions in the chip-tool area (Fig. 1a). Liquid flow rate and its pressure are the most important factors affecting the process of chip formation, and thus its shape and the effect of its breaking, as well as the mechanism of tool wear and its final life.

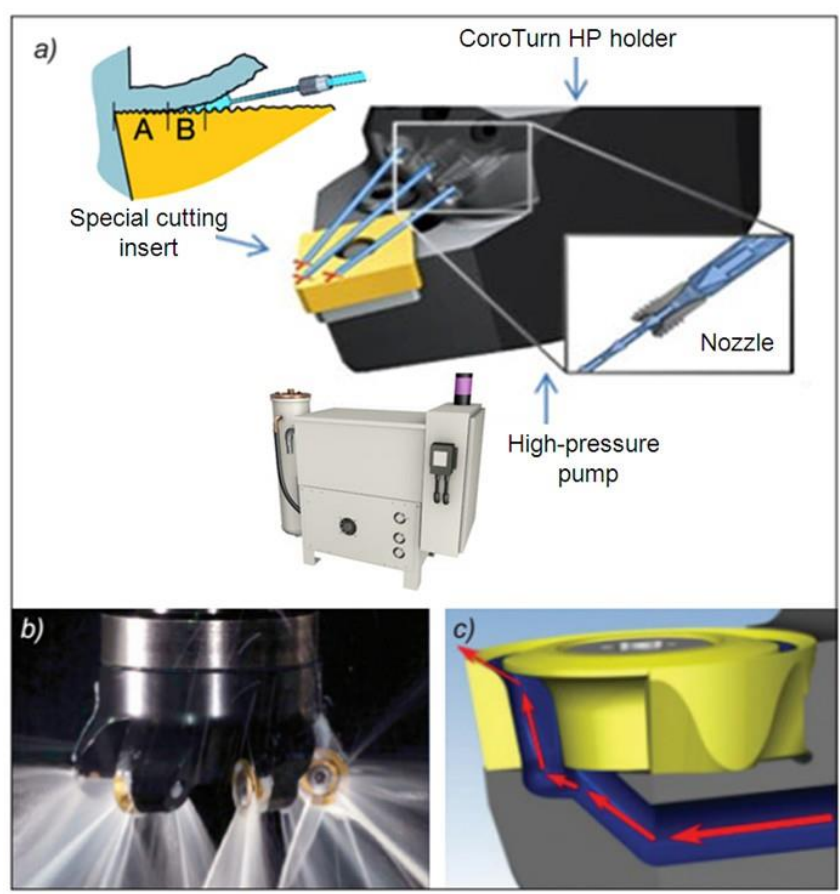

Fig. 1. The principle of creating a hydrodynamic wedge in the chiptool contact zone (a); CoroTurn HP head design with three nozzles $(b-c)$, Beyond Blast PCT (Precision Cooling Technology) cutter head $(b)$ with CCS supply through the channels in the cutting insert (c) from Kennametal [8]

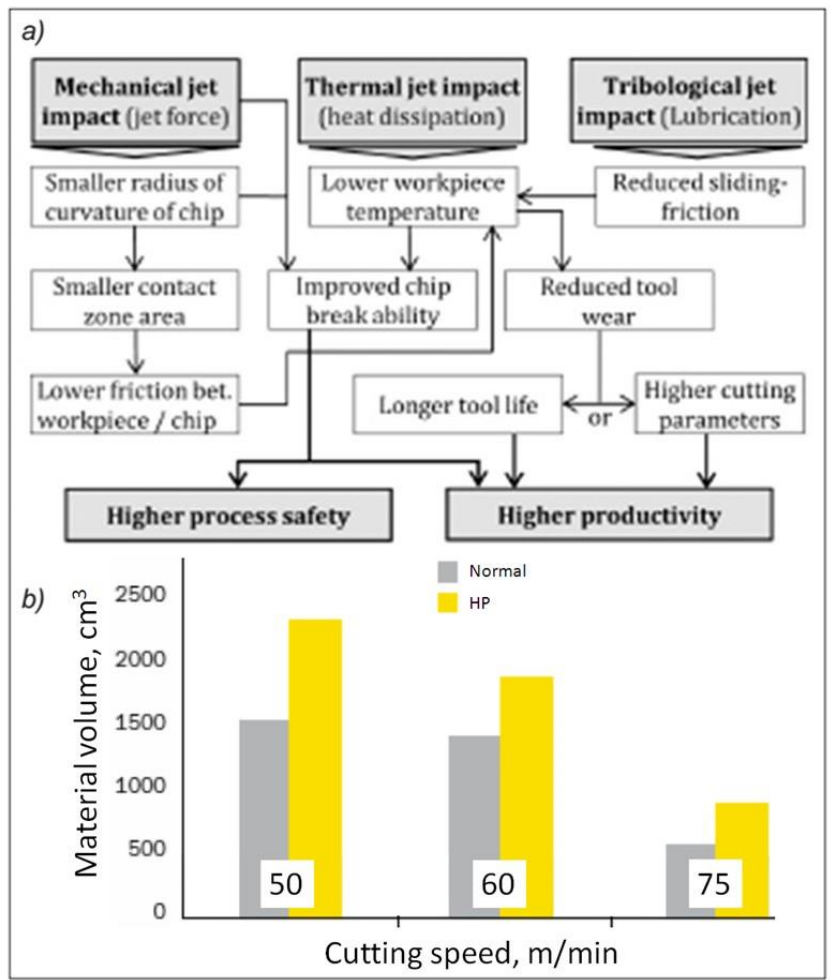

Fig. 2. Influence of the high-pressure liquid jet on the cutting process [14] (a) and comparison of the cutting performance of the Ti6Al4V alloy [8] $(b)$

There are also observed changes in the material structure and chip formed, related to significant mechanical, thermal and tribological changes of the process (see reducing the tool-chip contact length in fig. 1a). The final effect of these three interactions is shown in fig. 2 a.

It can be concluded that the hydrodynamic effect is similar to grooving cutting inserts (using RCT tools) [7]. For this reason, this method of assisting the process with technological media is also referred to as the term highpressure supply of CCS (high-pressure coolant supply) [4]. In the case of CoroTurn HP heads used in turning and boring tools systems, it is recommended to supply CCS under pressure $70 \div 80$ bar for stainless steel and $150 \div 200$ bar for duplex stainless steels - and HRSA alloys [8]. The recommended flow rate is $20 \mathrm{l} / \mathrm{min}$. Cutting operations performed under pressure above 300 bar are called cutting assisted with high-pressure liquid jet (HPJAM) or water jet (HPWJAM) [9].

The principle of the HPC process and head construction is shown in fig. 1a. In the case of Beyond Blast PCT (Precision Coolant Technology), CCS is delivered through special channels in the cutting insert at a low pressure of approx. 7 bar (fig. 1c), which however produces a similar effect as a pressure increase of approx. 70 bar in the external HPC supply. This solution resulted in increased tool life in the machining of titanium alloys by $70 \div 100 \%$ [8].

Fig. 3 shows the change in the chip shape in the grooving of the Inconel 718 alloy due to the increased pressure of the CCS jet to 80 and 300 bar. In fig. 3b, it can be observed that the increase in CCS pressure to 80 bar results in the disappearance of the formation of tangled chips that disturb the cutting process in automated machining. 


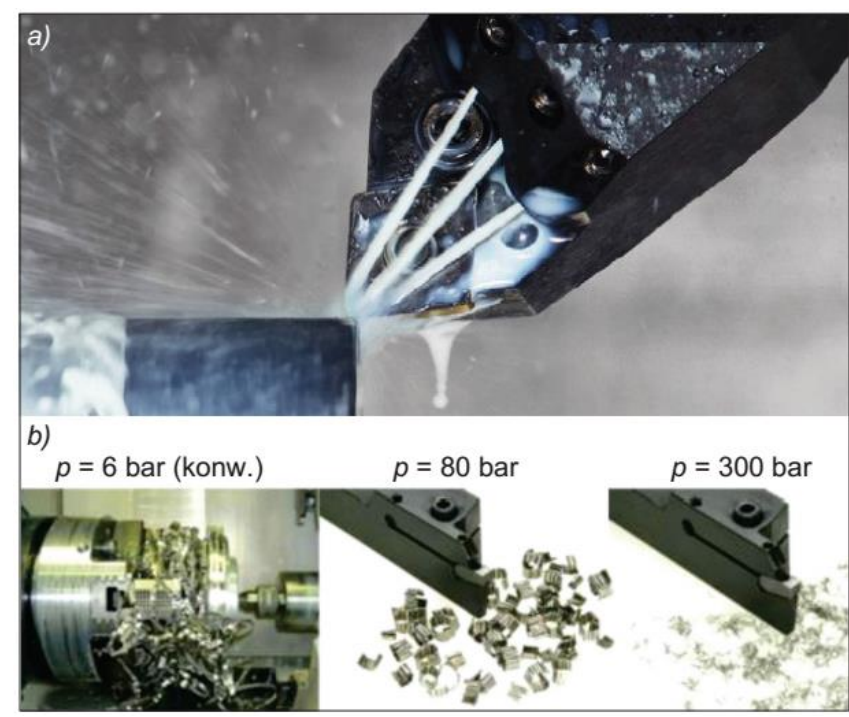

Fig. 3. Improvement of chip breaking during Inconel 718 grooving by supplying CCS under pressure 80 and 100 bar [4]. Machining conditions: cutting tool material - CBN, CCS - emulsion $8 \%, v_{\mathrm{c}}=$ $250 \mathrm{~m} / \mathrm{min}, f=0.1 \mathrm{~mm} / \mathrm{rev}, b=6 \mathrm{~mm}, a_{\mathrm{p}}=5 \mathrm{~mm}$ (conventional cooling) and $10 \mathrm{~mm}$ (HPC)

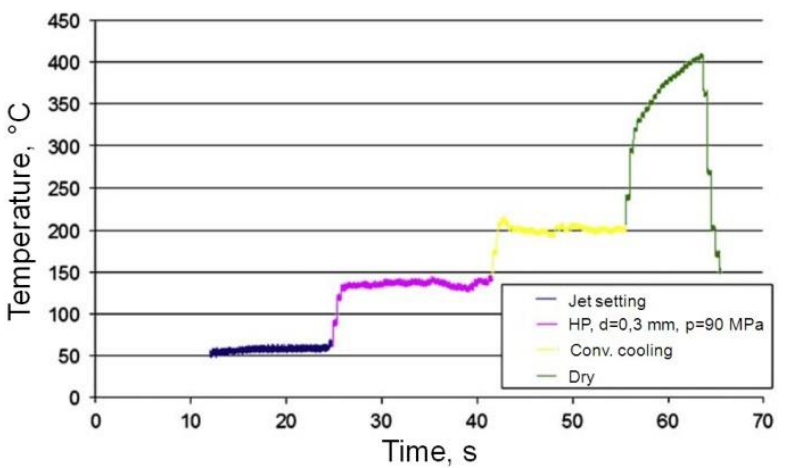

Fig. 4. Comparison of temperature values in the cycle of changing the cooling conditions when turning the Inconel 718 alloy. Machining conditions: $v_{\mathrm{c}}=50 \mathrm{~m} / \mathrm{min}, f=0.224 \mathrm{~mm} / \mathrm{rev}, a_{\mathrm{p}}=2 \mathrm{~mm}$ [9]

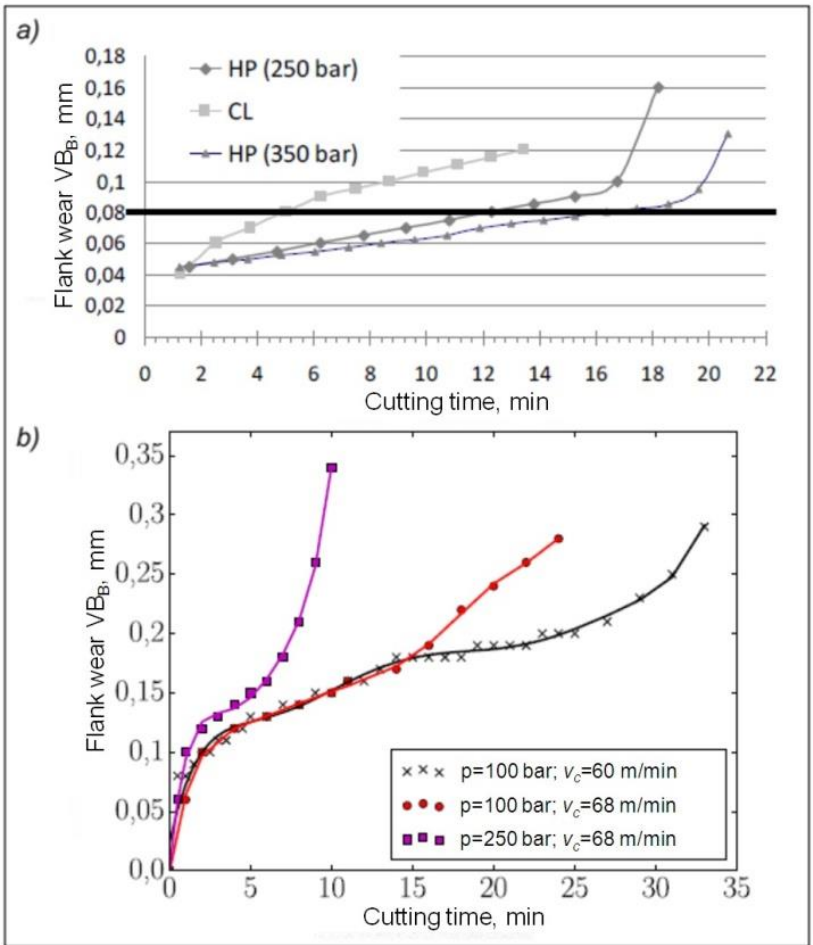

Fig. 5. Influence of CCS pressure on the tool wear in turning: a) duplex steel X2CrNiMo22-5, $f=0.15 \mathrm{~mm} / \mathrm{rev}, a_{0}=0.5 \mathrm{~mm} ; b$ ) titanium alloy Ti555-3, $f=0.1 \mathrm{~mm} / \mathrm{rev}, a_{p}=1.5 \mathrm{~mm}[10.11]$
On the basis of many years of experience, it can be concluded that the main application of the HPC technique is the machining of hard-to-cut materials in the aviation industry and turbine components. The low thermal conductivity of these materials causes that without a proper cooling strategy, accelerated and often catastrophic tool wear occurs. It was found that the cutting temperature can be reduced by $40 \div 50 \%[4,9]$. This confirms the recording of temperature changes under different machining conditions (during dry cutting the temperature rises almost four times when CCS stops under pressure) - fig. 4. For this reason it is possible to increase the cutting speed to the HSM limits when turning and milling titanium alloy Ti6Al4V and Inconel 718.

According to Sandvik Coromant, the machining removal rate for the Ti6Al4V titanium alloy increases by $50 \%$ at the same cutting speed and by $20 \%$ as a result of the increase in the cutting speed [8]. Under the HPJAM machining conditions from Figure 4, a 30\% reduction in cutting edge temperature compared to conventional cooling is achievable with a $350 \%$ reduction in CCS flow rate [9].

However, in the case of the Inconel 718 super alloy and a large group of steel, the tool wear during finishing can be reduced up to $350 \%$. The wear curves shown in fig. 5 confirm the strong dependence of wear on the cooling method and conditions when machining duplex stainless steel and Ti555-3 titanium alloy. This is accompanied by a clear decrease in the tensile residual stresses in the subsurface layer.

The investigations confirm the improvement of surface quality after turning (fig. 6) and milling and minimization of burr formation. In Poland, the HPC technique effectively supports, among others, cutting super alloys at the Pratt \& Whitney aerospace plant in Rzeszów [14].

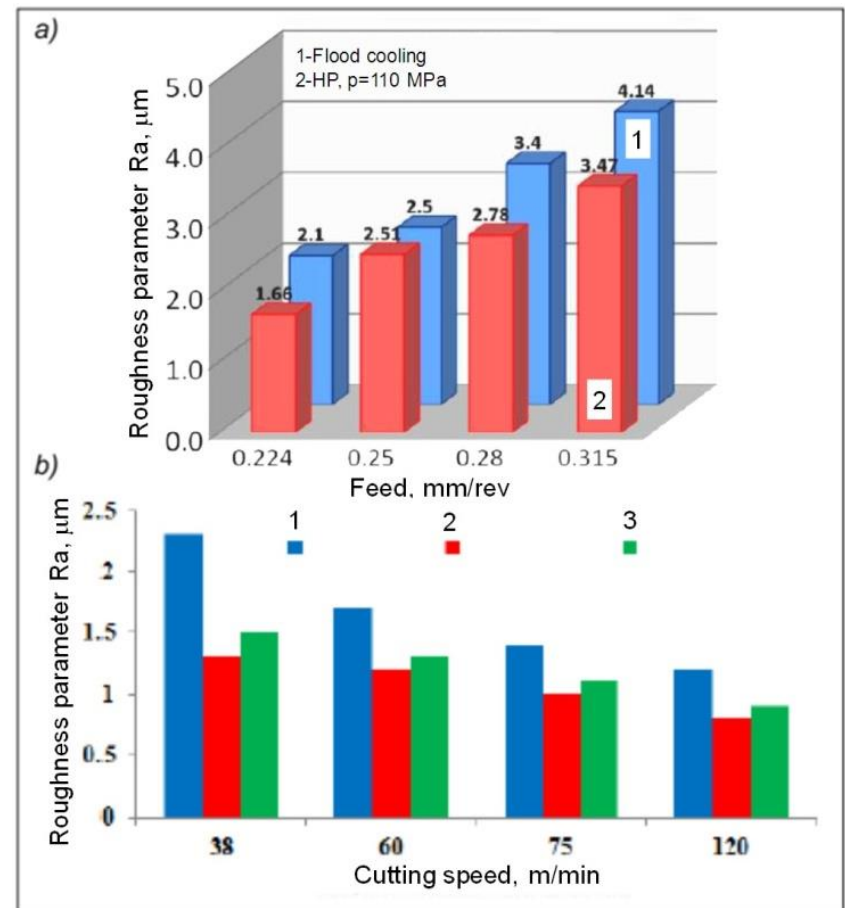

Fig. 6. Comparison of Ra surface roughness value after turning: a) Ck45 steel (58 HRC) with flood cooling and HPJAM with liquid pressure $p=110$ bar, $v_{c}=98.5 \mathrm{~m} / \mathrm{min}, a_{p}=2 \mathrm{~mm} \mathrm{[12]} \mathrm{;} \mathrm{b)} \mathrm{titanium}$ alloy TC9 (cooling methods: 1 - jet of cold air, 2 - flooding, 3 - jet of cold water) [13]

- Machining with minimal CCS / lubricant aerosol supply (MQL). Dry cutting is impossible in many operations. In the 1990s, work on minimizing the consumption of CCS led to the implementation of the opposite cooling technique (more precisely: machining with the minimum amount of lubricant in the coolant, MQL) [7]. It should be emphasized that 
depending on the function of the liquid medium provided, there is such minimal lubrication as well as cooling (MQC) when minimal emulsion, water or cooled / condensed air is supplied. If these two functions are simultaneous - as in the case of a cooling and lubricating aerosol - the concept of minimum cooling and lubrication (MQCL - minimum quantity cooling lubrication) is used. Usually in machining centers, the flow rate of the coolant is approx. $20 \div 100 \mathrm{l} / \mathrm{h}$, while in $\mathrm{MQL}$ installations it is only $0.03 \div 0.20 \mathrm{l} / \mathrm{h}$ (average less than $50 \mathrm{ml} / \mathrm{h}$ ). The basic applications of $\mathrm{MQL}$ concern the machining of holes (drilling, reaming, deep drilling, threading and thread cold-forming) as well as cutting in aluminum, steel and gray cast iron. Currently, fatty alcohols and synthetic esters (ester oils) are used as a lubricating medium, supplied in the form of aerosols or vapors [7].

In minimum lubrication systems (MS) there are two ways of supplying the lubricating fluid to the cutting edge: external and internal. In the external supply, an aerosol produced in a special installation is sprayed from one or several nozzles located close to the cutting edge, and the positioning of the nozzles is very important for the efficiency of cutting tool lubrication. This technique is used in machine tools that do not have an internal CCS supply installation, e.g. during parting, face milling and face milling and turning. At higher values of $I / D>3$ it becomes necessary to internally delivery the lubricant through the spindle and channels in the tool. One- or two-channel systems are then used.

Technical issues related to MQL technology are certainly well known to mechanical engineers from previous review articles. In this study, the effectiveness of the MQL technique will be compared to the effects of other CCS dosing and delivery methods.

As mentioned, in the machining of hard-to-use aerospace alloys, the HPC strategy is generally applied, however there are promising signals indicating the positive effects of using the MQL technique (used on a large scale in machining aluminum alloys) [15]. This is possible provided that appropriate cutting tool materials / coatings and cutting tool geometries are selected.

For example: in the finishing of nickel alloys, the MQL technique works well for cutting inserts with $\mathrm{TiCN} / \mathrm{Al}_{2} \mathrm{O}_{3} / \mathrm{TiN}$ multilayer coating $\left(v_{\mathrm{c}}=60 \mathrm{~m} / \mathrm{min}\right)$, and in milling - for ceramic inserts reinforced with $\mathrm{SiC}$ and SiAION whiskers $\left(v_{c}\right.$ $=100 \div 500 \mathrm{~m} / \mathrm{min}$ ). In the case of Ti6Al4V titanium alloy machining, the MQL is tested with the combination of microtexture of the rake face, which results in a significant decrease in the cutting temperature and the component cutting forces. In such demanding machining as cutting CFRP composites, it is unacceptable to use flood cooling, only MQL is possible, provided that very small oil particles are provided in the stream at high speed or the coherent stream is created with minimal swirls.

\section{Methods of cryogenic machining}

Cryogenic machining/cutting is classified in the group of processes assisted by gaseous media, cooled to cryogenic temperature [4]. The origin of cryogenics is assumed to correspond to a temperature of $-150{ }^{\circ} \mathrm{C}(123 \mathrm{~K})$, although CASA (Cryogenic American Society of America) defines it below $120 \mathrm{~K}\left(-153^{\circ} \mathrm{C}\right)$ and NIST below $-180{ }^{\circ} \mathrm{C}$ [5]. This corresponds to the temperature below the boiling point of many gases (helium, hydrogen, oxygen, nitrogen and normal air).

Cryogenic media with technological significance are liquid nitrogen $\left(\mathrm{LN}_{2}\right)$ with a temperature of $-186{ }^{\circ} \mathrm{C}$, helium and cooled carbon dioxide $\left(\mathrm{LCO}_{2}\right)$ with a temperature of -50 $\div-78{ }^{\circ} \mathrm{C}$. This means that, contrary to the accepted definitions in technological practice, cryogenics refers to cooling media at a temperature below $0{ }^{\circ} \mathrm{C}$.

Cryogenics is recognized as the primary means in the concept of clean/sustainable machining $[5,6,16]$. This thermal effect changes the properties of the tool material and workpiece material - at the same time - beneficial for tool life, chip morphology and the functionality of the machined surface (e.g. increasing fatigue strength, corrosion and abrasion resistance) - intensive dissipation of heat from the cutting zone. The use of cooling cryogenic media has a similar effect as the combination of dry machining and rapid cooling.

Hybrid cooling strategies are also being developed, in which the cryogenic effect is supported by the lubrication of oil aerosol suspension (MQL) with the $\mathrm{LN}_{2}$ or $\mathrm{LCO}_{2}$ stream.

Tab. II lists the advantages and disadvantages of cryogenic treatment. Apart from the discussion, there are benefits regarding environmental protection and social aspects (the most important is the lack of toxic impact on employees' health). On the other hand, the economic side of the process is questioned because of the high price of cryogenic media (high flow rate is required to cool the cutting tool edge, because this effect expands on the workpiece and machine tool components) and the additional costs associated with storage and transport.

TABLE II. List of advantages and disadvantages of cryogenic machining [16]

\begin{tabular}{|c|c|c|}
\hline Criteria & Advantages & Disadvantages \\
\hline Costs & $\begin{array}{c}\text { Higher cutting speed / } \\
\text { longer durability }\end{array}$ & Cost of the medium \\
\hline Product quality & $\begin{array}{c}\text { Better surface } \\
\text { quality }\end{array}$ & $\begin{array}{c}\text { Less dimensional } \\
\text { accuracy }\end{array}$ \\
\hline $\begin{array}{c}\text { Environment / } \\
\text { society }\end{array}$ & $\begin{array}{c}\text { Clean production } \\
\text { environment }\end{array}$ & $\begin{array}{c}\text { Defrosting / } \\
\text { corrosive effects }\end{array}$ \\
\hline
\end{tabular}

- Cryogenic machining using cooled $\mathrm{CO}_{2}$. In this case, the Joule-Thomson effect is used, according to which liquid $\mathrm{CO}_{2}$ at $-78.5^{\circ} \mathrm{C}$ boils (foaming) at atmospheric pressure, creating a mixture of snow foam $\mathrm{CO}_{2}(60 \%)$ and gas $(40 \%)$. It is stored in the liquid state at a pressure of approx. 50 bar. Cooling is the result of rapid expansion due to evaporation (sublimation) when liquid $\mathrm{CO}_{2}$ exits the nozzle. For this reason, the position of the nozzle relative to the cooled zone is very important. An important factor in the effective cooling of the $\mathrm{CO}_{2}$ stream is the flow rate, the increase of which results in increased dissipation of heat from the cutting zone [17].

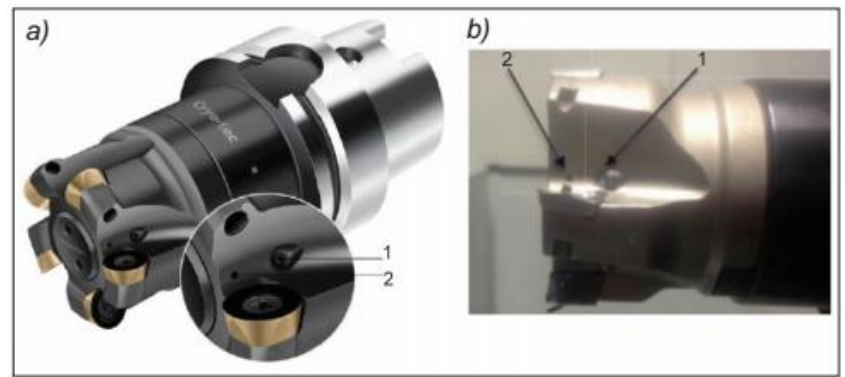

Fig. 7. Designs of cutting tools (cryo-tec type) for optional delivery of various media through internal channels: a) copy milling cutter (1 - air, emulsion, aerosol, $2-\mathrm{CO}_{2}$ ) [18], b) face milling cutter (1 - MQL and/or air, $\left.2-\mathrm{CO}_{2}\right)[19]$

For machining, cutting tools such as the cryo-tec milling cutters shown in fig. 7 are increasingly used, with the option of supplying various cooling / lubricating media - air, emulsion, aerosol or $\mathrm{CO}_{2}$.

The wear curves obtained after face milling (cutter from fig. 7b) of Ti6Al4V titanium alloy using various cooling techniques - flood cooling, MQL, cooled $\mathrm{CO}_{2}$ and hybrid $\left(\mathrm{CO}_{2}+\mathrm{MQL}\right.$ and $\mathrm{CO}_{2}+$ air $)$ - are shown in fig. $8 \mathrm{a}$. 
In comparative tests for the wear indicator $V_{\mathrm{BB}}=0.2 \mathrm{~mm}$ a constant cutting speed $v_{\mathrm{C}}=100 \mathrm{~m} / \mathrm{min}$ was applied. Fig. $8 \mathrm{a}$ shows that the tool life $T=30 \mathrm{~min}$ was obtained by flooding with emulsion and under pressure (curves 2 and 1 ). Cryogenic $\mathrm{CO}_{2}$ cooling (curve 5) did not allow limiting the tool wear, even when compared to dry machining. On the other hand, $\mathrm{CO}_{2}+\mathrm{MQL}$ hybrid cooling (curve 6 ) proved to be effective, but for a shorter tool life of approx. 15 minutes [19]. For this reason, the tool life periods for different cutting speeds have been estimated in fig. 8b. It can be concluded that the addition of $\mathrm{CO}_{2}$ to the aerosol increases the tool's lifetime by an average of $30 \%$, but at lower cutting speeds (for $v_{\mathrm{c}}=100 \mathrm{~m} / \mathrm{min}$, the MQL method is more effective).

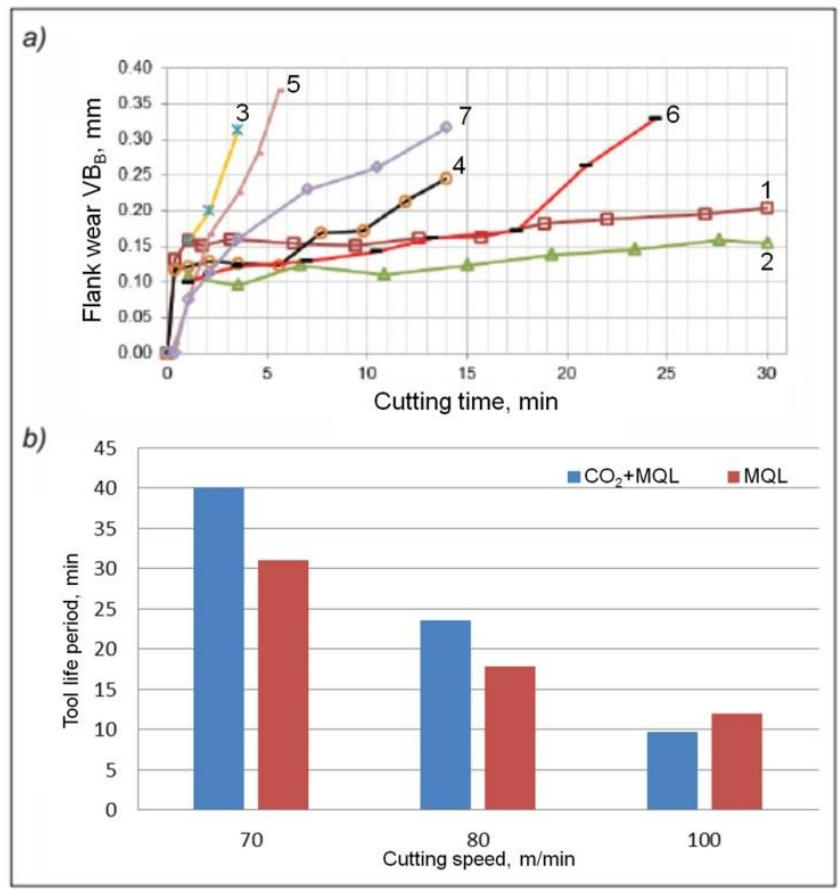

Fig. 8. Comparison of the effects of various cooling/lubrication methods in relation to wear for the cutting speed $v_{\mathrm{c}}=100 \mathrm{~m} / \mathrm{min}$; designation of cooling methods: 1 - HP with medium pressure, 2 flooding, 3 - dry, 4 - MQL, $5-\mathrm{CO}_{2}, 6-\mathrm{CO}_{2}+\mathrm{MQL}, 7-\mathrm{CO}_{2}+$ air (a) and tool life $(b)$ [19]

- Cryogenic machining with cryogenic $\mathrm{LN}_{2}$ nitrogen. It has been documented that the use of $\mathrm{LN}_{2}$ in the cutting process contributes to the reduction of friction and crater formation on the rake face, as well as the reduction of plastic deformation and abrasive wear of the flank face. This applies to the machining of titanium alloys, super alloys (e.g. Inconel 718), shape memory alloys, magnesium alloys, CoCr-Mo bio-alloys, composites based on metal, hard steels and cast iron as well as medical materials [5].

The state of prevalence of the cryogenic cooling technique with respect to the type of material and operations is shown in fig. 9. It dominates hard steel turning, but the lack of drilling is noticeable due to the difficulty in fitting the nozzles supplying the cryogenic medium to the cutting zone. In turn, the machining of ductile materials and polymer materials (usually micro-machining) involves the material being transformed into a fragile state. There is even a concept of cooling the formed chip, which in a fragile state will be more easily broken. Very demanding materials are titanium and nickel alloys and only - respectively - about $13 \%$ and $6.5 \%$ of the research concerns their cryogenic milling. However, there are real reasons to improve machinability and reduce the machining costs of these materials [20]. It should also be emphasized that $68 \%$ of materials used in cryogenic machining are sintered carbides, of which $1 / 3$ are coated carbides. This is easily explained by the increased tool life.

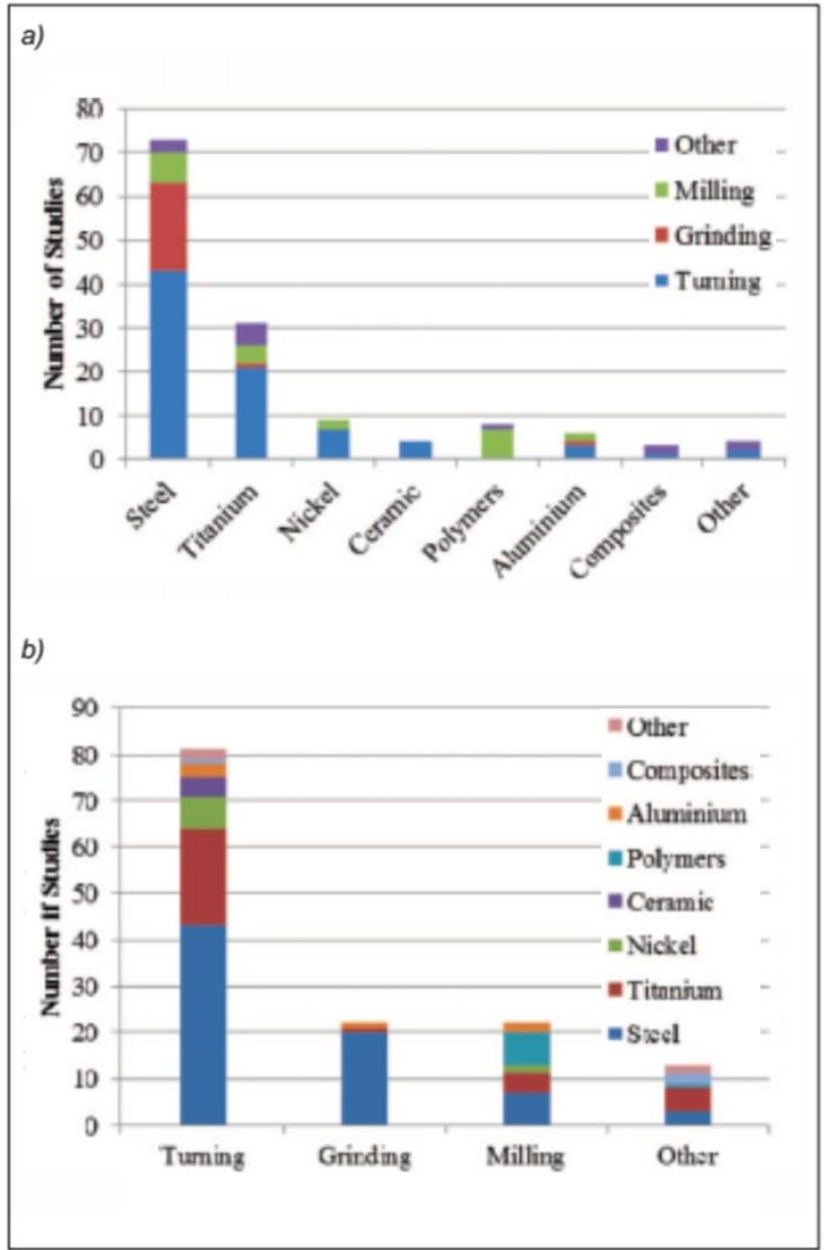

Fig. 9. Application range of cryogenic cutting with reference to: a) machined materials, b) machining operations - based on the number of research works [21]

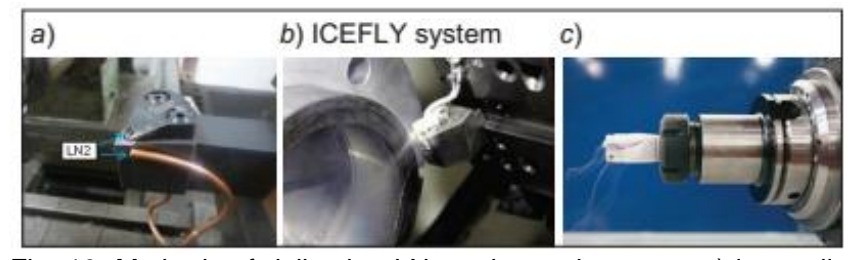

Fig. 10. Methods of delivering $\mathrm{LN}_{2}$ to the cutting zone: a) internally and b) externally [18]; c) through the spindle for cryogenic MQL cooling [21]

Methods of bringing liquid nitrogen into the cutting zone are shown in fig. 10.

For example, in the cryogenic machining of titanium alloys, the machining removal rate may increase by up to two times. On the one hand, the components of the cutting force increase as a result of hardening of the workpiece, and on the other hand, the tool life increases (even by a factor of ten) due to intensive heat dissipation through the cryogenic medium.

Fig. 11 compares the intensity of the surface wear growth of the milling cutter in cryogenic milling of Ti6Al4V titanium alloy using $\mathrm{LCO}_{2}$ and $\mathrm{LN}_{2}$.

Less and even wear is visible when liquid nitrogen is injected into the contact zone instead of $\mathrm{LCO}_{2}$. This effect is explained by the creation of liquid/gaseous layers between the sliding surfaces of the tool and chip, which reduces friction (values of $\mu$ to $0.3 \div 0.4$ ) [20]. Cryogenic machining is an effective way to improve the machinability of materials with extremely poor machinability, such as intermetallics (titanium aluminides) used more and more often on gas turbine blades. 

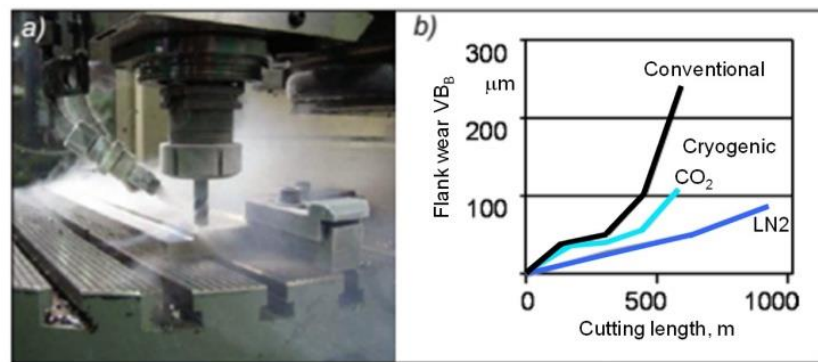

Fig. 11. Cryogenic milling of titanium alloy $\mathrm{Ti}_{6} \mathrm{Al}_{4} \mathrm{~V}\left(D_{\mathrm{f}}=12 \mathrm{~mm}, a_{\mathrm{e}}=\right.$ $8 \mathrm{~mm}, a_{\mathrm{p}}=5 \mathrm{~mm}, v_{c}=100 \mathrm{~m} / \mathrm{min}, f_{z}=0.03 \mathrm{~mm}$ ) (a) and comparison of wear increase for cooling with $\mathrm{CO}_{2}$ stream and $\mathrm{LN}_{2}$ (b) $[5,6]$

Fig. 12 shows the effects of applying different cooling strategies (including $\left.L_{2}\right)$ to tool wear $\left(V_{B_{B m a x}}\right.$ indicator) in cutting intermetallic $\gamma$-TiAIN with HW-P10 carbide tool. It can be clearly seen that the $\mathrm{LN}_{2}$ leads to a reduction in tool wear by approx. $60 \%$ compared to gravity cooling.

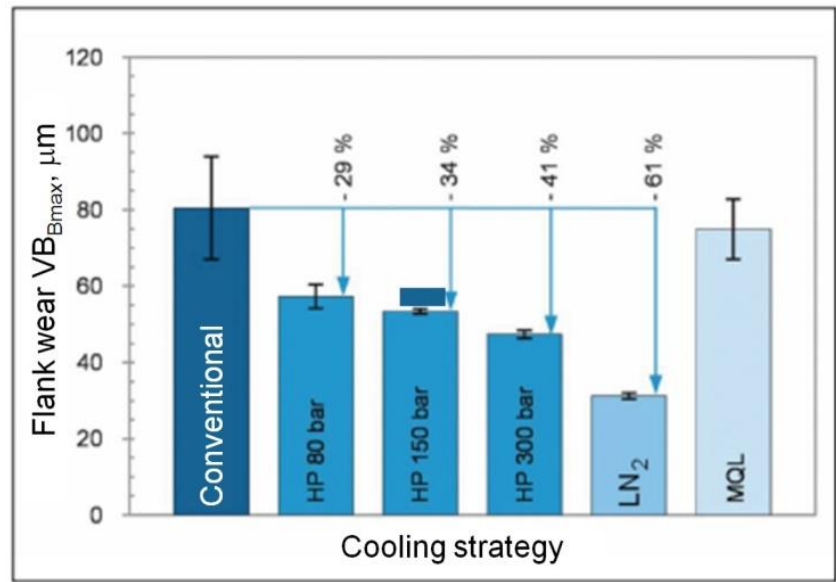

Fig. 12. Comparison of tool wear in cutting intermetallic $y$-TiAIN with HW-P10 carbide tool with various cooling methods; cutting parameters: $v_{\mathrm{c}}=80 \mathrm{~m} / \mathrm{min}, f=0.1 \mathrm{~mm} / \mathrm{rev}, a_{\mathrm{p}}=0.25 \mathrm{~mm}[6,8]$
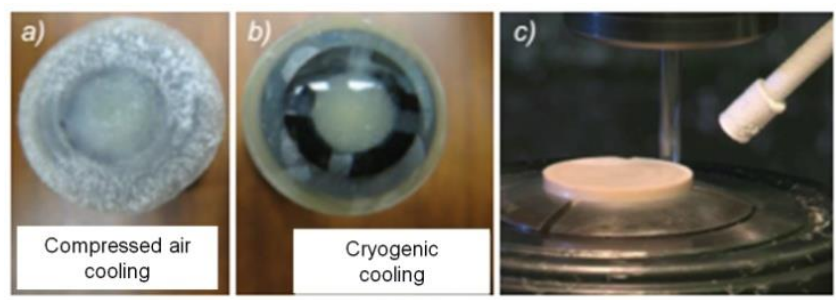

Fig. 13. Intraocular lens made of thermoplastic PMMA biopolymer after machining: a) conventional with compressed air cooling and $b$ ) cryogenic tool type ICEFLY from fig. 10b [22]; c) cryogenic cooling of the workpiece

Cryogenic machining (fig. 9b) is also used to machine ceramics with PCBN tool or polymer materials, e.g. PMMA thermoplastic - methyl polymethacrylate, used for eye pupil implants, so-called implanted intraocular lens (IOL). In these cases it is required to significantly improve the surface smoothness.

The cryogenic turning effects of the PMMA polymer are shown in Figures $13 \mathrm{a}$ and $\mathrm{b}$. Because the material undergoes a glassy state at $-40{ }^{\circ} \mathrm{C}$, a mirror hydrophilic surface (fig. 13b) is obtained with much lower roughness (the $R q$ parameter is $40 \%$ lower).

- Optimization of machining using various cutting and lubricating media. When implementing new manufacturing processes, it is important to choose optimal conditions according to different optimization criteria. In the case of cutting processes, these can be costs and energy consumption index (usually energy consumption) of the process [7, 23]. An interesting and important issue is the inclusion of cooling strategies as an optimization criterion.

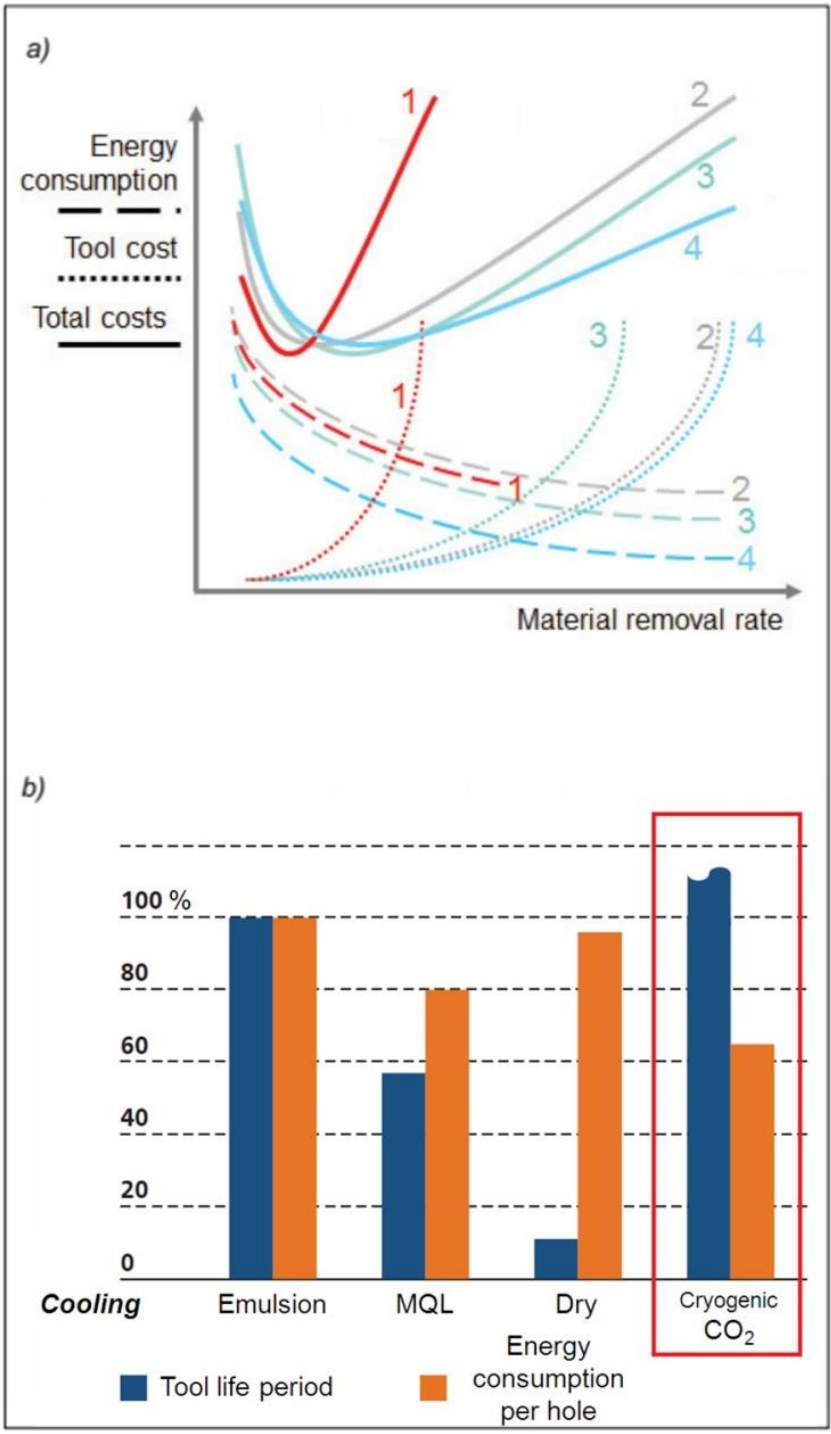

Fig. 14. Drilling of EN-GJL 250 cast iron using various cooling strategies: a) comparison of energy consumption and costs; designation of cooling methods: 1 - dry, 2 - emulsion, 3 - MQL, 4 cryogenic; b) tool life periods [24, 25]

Fig. 14a presents the assessment of energy consumption and costs as a function of volumetric machining removal rate for drilling holes in gray cast iron grade EN-GJL 250. Comparatively, dry machining, emulsion cooling, MQL technique and $\mathrm{CO}_{2}$ cryogenic cooling were used.

Higher machining rate generates higher tooling costs due to the shortening of tool life and in this aspect it is more advantageous to choose emulsion cooling or cryogenic $\mathrm{CO}_{2}$ (this trend is confirmed in fig. $14 b$, but the energy consumption per one hole is clearly lower). Energy consumption decreases with increasing machining rate and in this case cryogenic cooling proved to be the most favorable. The lowest total costs were obtained for different cooling strategies, but the highest machining rate for this criterion also appears in the case of $\mathrm{CO}_{2}$ cooling (this also applies to the lower machining rate determined for the MQL strategy). Machining with emulsion cooling and MQL can be considered for medium, and dry - for low machining rate.

The cited analysis clearly shows the sustainability of cryogenic processing, since the savings concern not only environmental protection and energy consumption, but also costs and time. 


\section{Conclusions}

- Machining assisted by technological media is still developed and is an important element of hybrid material shaping. Especially the use of cryogenic media - liquid and gas - contributes to the development of clean, sustainable manufacturing / machining processes.

- The effectiveness of different cooling/lubrication strategies should be considered in the context of tool wear. For this reason it is very important to adapt the cooling and lubrication effects to the cutting conditions. A good solution may be hybrid media based on cryogenic components, such as $\mathrm{CO}_{2}+\mathrm{MQL}$ or $\mathrm{LN}_{2}+\mathrm{MQL}$.

- The choice of cooling strategy (confirmed for drilling holes in gray cast iron) should be considered both in the function of energy consumption and costs. In this aspect, $\mathrm{CO}_{2}$ cryogenic cooling is a good choice for high machining removal rate. In turn, dry machining is recommended for small, and emulsion cooling and MQL for medium machining removal rate.

- Sustainability of cryogenic machining extends to savings not only for environmental protection and energy consumption, but also for costs and time.

\section{REFERENCES}

1. Grzesik W. „Hybrydowe procesy obróbki ubytkowej. Definicje, zasady tworzenia i znaczenie w przemyśle". Mechanik. 91, 56 (2018): pp. 338-341.

2. Grzesik W. "Hybrydowe procesy kształtowania wyrobów, integrujące techniki przyrostowe i ubytkowe". Mechanik. 91, 7 (2018): pp. 468-475.

3. Grzesik W. „Polepszanie jakości technologicznej i użytkowej części z materiałów utwardzonych. Cz. I. Obróbka wspomagana i hybrydowa". Mechanik. nr 7 (2011): pp. 564-569.

4. Lauwers B., Klocke F., Klink A., Tekkaya A.E., Neugebauer R., McIntosh D., "Hybrid processes in manufacturing". Annals of the CIRP Manufacturing Technology. 63/2 (2014): pp. 561583.

5. Jawahir I.S., Attia H., Biermann D., Duflou J., Klocke F., Meyer D., Newman S.T., Pusavec F., Putz M., Rech J., Schulze V., Umbrello D. "Cryogenic manufacturing processes". Annals of the CIRP - Manufacturing Technology. 65/2 (2016): pp. 713736.

6. Grzesik W. „Wizje i strategie wytwarzania, cz. I i II”. Mechanik. 83, 3, 4 (2010): s. 145-148 (cz. I); pp. 232-239.

7. Grzesik W. „Podstawy skrawania materiałów konstrukcyjnych”. Warszawa: PWN, 2018.

8. Materiały firmowe: High pressure coolant machining, www.sandvik. coromant.com; Precision Cooling Technology, www.kennametal.com.

9. Courbon C., Kramar D., Krajnik P., Pusavec F., Rech J., Kopac J. "Investigation of machining performance in highpressure jet assisted turning of Inconel 718: An experimental study". Int. J. Machine Tools and Manufacture. 49 (2009): pp. 1114-1125.

10. Braham-Bouchnak T., Germain G., Robert P., Lebrun J.L. "High pressure water jet assisted machining of duplex steel: machinability and tool life". Int. Journal of Material Forming. 3 (2010): pp. 507-510.

11. Ayed Y., Germain G. "High-pressure water-jet-assisted machining of Ti555-3 titanium alloy: investigation of tool wear mechanisms. Int J. Advanced Manufacturing Technology. 96 (2018): pp. 845-856.

12. Globočki Lakić G., Sredanović B., Kramar D., Kopač J. "Possibilities of application of high pressure jet assisted machining in hard turning with carbide tools". Tribology in Industry. 39 (2017): pp. 238-247.

13. Wstawska I., Ślimak K. "The influence of cooling techniques on cutting forces and surface roughness during cryogenic machin- ing of titanium alloys". Archives of Mechanical Technology and Materials. 36 (2016): pp. 12-17.

14. Laskowski P., Krupa K., Habrat W., Przestacki D., Sieniawski J. „Toczenie stopu Ti-6Al-4V z zastosowaniem wysokiego ciśnienia cieczy chłodząco-smarującej“. Mechanik. 87, 8-9 CD (2014): pp. 403-410.

15. M'Saoubi R., Axinte D., Leung Soo S., Nobel Ch., Attia H., Kappmeyer G.,Engin S., Wei-Ming S. "High performance cutting of advanced aerospace alloys and cmposite materials". Annals of the CIRP Manufacturing Technology. 64, 2 (2015): pp. 557-580.

16. Lu T., Dillon O.W., Jawahir I.H. "A thermal analysis framework for cryogenic machining and its contribution to product and process sustainability". Proc. $11^{\text {th }}$ Global Conference on Sustainable Manufacturing - Innovative Solutions, Berlin (2013): pp. 262-267.

17. Sadik M.I., Isakson S., Malakizadi A., Nyborg L. "Influence of coolant flow rate on tool life and wear development in cryougenic and wet milling of Ti-6Al-4V". Procedia CIRP. 46 (2016): pp. 91-94.

18. Stefansson T. "Application of Cryogenic Coolants in Machining Processes". Stockholm: KTH, 2014.

19. Tapoglou N., Lopez M.A., Cook I., Taylor Ch.M. "Investigation of the influence of $\mathrm{CO}_{2}$ coolant application on tool wear". Procedia CIRP. 63 (2017): pp. 745-749.

20. Shokrani A., Dhokia V., Munoz-Escalona P., Newam S.T. "State-of-the-art cryogenic machining and processing". Int. Journal of Computer Integrated Manufacturing. 26 (2013): pp. 616-648.

21. Prins C., Treurnicht N.F. "An overview of advanced cooling techniques for titanium alloy machining in aerospace". SAll25 Proceedings, 2013 (online).

22. Knopf J., Grimm L., Ghosh R., Gibson D. "Cryogenic machining of PEEK". Proc. $1^{\text {st }}$ PEEK Conf., Philadelphia, 2013.

23. Grzesik W., Energy consumption optimization in machining processes, in Davim J.P (ed.) Metal Cutting Technologies. Progress and Current Trends, pp.36-56.

24. Neugebauer R., Drossel W., Wertheim R., Hochmuth C., Dix $M$. "Resource and energy efficiency in machining using highperformance and hybrid processes". Procedia CIRP. 1 (2012): pp. 3-16.

25. Hybrid machining processes in cutting technology, Fraunhofer IWU, www.iwu.fraunhofer.de. .

Translation of scientific articles, their computer composition and publishing them on the website www.mechanik.media.pl by original articles in Polish is a task financed from the funds of the Ministry of Science and Higher Education designated for dissemination of science.

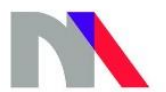
and Higher Education 